\title{
PBL: Pedagogy, Partnership and Information Literacy
}

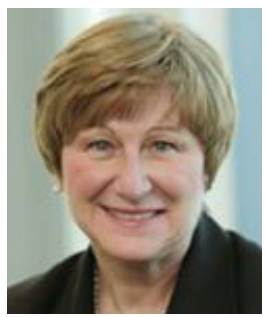

\section{Lee Anne Xippolitos}

School of Nursing, Stony Brook University, USA

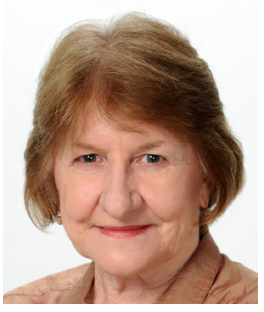

\section{Margaret McMillan}

School of Nursing and Midwifery, University of Newcastle, Australia

In 2016, Stony Brook University, School of Nursing, in collaboration with Stony Brook Medicine, participated in a strategic planning process resulting in the identification of two major areas of strength. The first strength is success in scholastic endeavors associated with distance education and the second strength is our distinction in areas related to clinical practice. Taking these two elements into consideration, our School made a strategic decision to embark on a mobile learning initiative that would embed clinical expertise into an educational platform that leveraged cutting edge technology to increase academic success. This objective soon took form as a School initiative to become an Apple Distinguished School. This project is now affectionately known as, "March to Apple". The School aimed to

- Update the learner management system to an application that allows for innovation and creativity

- Seek current and specialized software to enhance current teaching-learning practices and increase the quality and depth of the educational environment

Faculty participation over a two years aimed to 'Create transformational educators', who would become 'Deeply engaged with technology and student engagement' and would become 'Experts on integrating technology into learning environments'. Inherent in involvement with the project was a willingness to demonstrate best practice and a commitment to collecting evidence of student success with learning outcomes.

As part of our "March to Apple", beginning in 2018 each undergraduate, graduate and doctoral student at the School of Nursing's orientation now receives an iPad. This mobile device is utilized as a learning tool throughout the student's academic experience. Mobile technology is part of the daily lives of all College Students and also of many of the people for whom they provide care. According to a 2016 Educause Report, 83 percent of adults between the ages of 18 and 29 own a smart phone and nearly 47 percent own a tablet. Health service providers in-

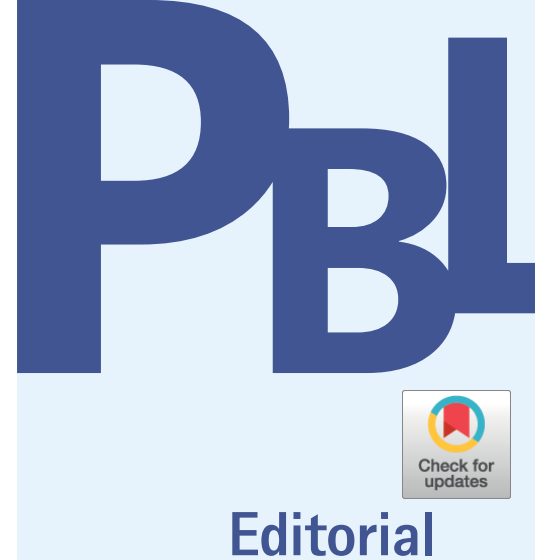

pISSN 2288-8675 • elSSN 2508-9145

J Probl Based Learn 2019;6(1):1-2 https://doi.org/10.24313/jpbl.2019.00156

Received: April 22, 2019

Accepted: April 26, 2019

Corresponding author:

Lee Anne Xippolitos

Stony Brook University, School of Nursing Nicolls Road, Stony Brook, 11709, USA

Tel: +1-631-444-1041

E-mail: Lee.Xippolitos@

stonybrookmedicine.edu
(C) Copyright 2019 International Society for Problem-Based Learning

(c) This is an Open Access article distributed under the terms of the Creative Commons Attribution Non-Commercial License (http://creativecommons.org/licenses/ by-nc/4.0/) which permits unrestricted non-commercial use, distribution, and reproduction in any medium, provided the original work is properly cited. 
teract with the consumers using a range of information technology. This technology has changed the manner in which students communicate, gather information, analyze data and eventually learn. Establishing patterns of behavior enhances lthe likelihood of information fluency and lifelong learning. Additionally, mobile technology can record raw observations, breakdown geographic boundaries and provide for access regardless of time. This ever changing mobile landscape has provided for new opportunities to enrich the academic experience for students, faculty members and support staff.

Faculty development became a key factor in implementing this project. This is a commitment made by the School to assure that the "March to Apple" is a success. Building a community of academic expertise that focuses on technology as an adjunct to learning activities is not to be minimized. Serious college Professors today need to stay current and well-informed of existing and changing technologies. Faculty have found that as technology advances, their ability to grow as educators has multiplied. Innovation and creativity abound in classrooms, whether physical or virtual, when a Faculty member utilizes technology as a catalyst to create curiosity and to inspire future nurses. Health professionals (both educators and clinicians) need to accept that knowledge becomes rapidly outdated but also that the ability to question the worthiness of sources of information is critical to outcomes for patients, clinicians and educators.

The "March to Apple" is a dynamic journey! Each phase brings conquered milestones as well as new challenges to the School. However, the School's strategic goal "to strengthen the School's technology infrastructure to ensure accessibility, and support excellence in the academic enterprise by delivering new and expanded technologies" is being realized each and every day. It is a pleasure to bear witness to that! However all academics embracing technology also need to be mindful of its use in fostering deeper learning emerging from sound pedagogy and well structured instructional and curriculum design (Park et al 2016). Graduate learning outcomes need to include technological abilities but also an an ability to fully appreciate the relevance of information to the situations that demand professional judgment and decisions about care.

\section{REFERENCES}

EDUCAUSE. (2017). 2016 EDUCAUSE Core Data Service (CDS) Benchmarking Report. Retrieved from https://library. educause.edu/resources/2017/4/2016-educause-core-dataservice-cds-benchmarking-report

Park, M. Y., Conway, J., \& McMillan, M. (2016). Enhancing Critical Thinking through Simulation. Journal of Problem-based Learning, 3(1), 31-40.

Xippolitos, L. A. (2018). PBL and Edu-Tech The 12th Halla-Newcastle PBL International Symposium. Halla Newcastle PBL Education and Research Center, Cheju Halla. South Korea. 